\title{
BARRICADA, BANDEIRAS, ESCOLA, JÓQUEI-CLUBE: ATIVIDADES MATEMÁTICAS PARA PESSOAS NA TERCEIRA IDADE
}

\author{
Luciano Feliciano de Lima ${ }^{1}$ \\ Miriam Godoy Penteado ${ }^{2}$
}

\begin{abstract}
RESUMO: O artigo apresenta uma discussão sobre atividades matemáticas realizadas com um grupo de 22 pessoas, idosos e adultos maduros, participantes de um projeto de extensão universitária em uma cidade do interior do Estado de São Paulo. O intuito é entender como proposta como Conversas sobre matemática pode ser uma possibilidade para pessoas na terceira idade. As atividades foram desenvolvidas por meio de uma abordagem investigativa, visando promover uma participação ativa dos envolvidos. Elas foram organizadas considerando-se a heterogeneidade em relação aos anos de escolaridade e às condições físicas do grupo. Ao longo do texto, são feitas considerações sobre uma atividade que envolveu o uso de blocos lógicos na exploração de formas geométricas. Neste trabalho, da parte dos idosos, houve a formulação de questões para entender o que era para ser feito; a elaboração de conjecturas como possibilidades de solução; o teste e o refinamento das questões e conjecturas anteriores; e a comunicação dos resultados. Entende-se que as Conversas podem fazer parte do rol de atividades de idosos se: i) forem entendidas como uma ação comunicativa; ii) for valorizada uma abordagem com investigações matemáticas de assuntos variados, utilizando diferentes recursos; iii) os participantes aceitarem o convite e envolverem-se nas Conversas.
\end{abstract}

PALAVRAS-CHAVE: Educação matemática. Educação de idosos. Extensão universitária.

Barricade, flags, school, jockey club: mathematics activities for elderly people

\begin{abstract}
This article presents a discussion on mathematical activities performed by a group of 22 people, elderly and mature adults, who participate in a university extension project in a city of São Paulo State. The aim is to understand how Conversations about math (Conversas sobre matemática) may be a possibility for elderly people. The activities were developed through an investigative approach to promote the active participation of those involved. They were organized according to the heterogeneity regarding schooling years and physical condition of the group. It was made considerations about the activity that involved the use of logic blocks for the study of geometric shapes. During the activity, the group had the opportunity of making questions in order to understand what was to be done, the development of conjectures as possible solutions, testing and refinement of previous questions and conjectures, and reporting results. Conversations can be part of the list of activities for elderly people if: i) they are understood as a communicative action, ii) it is valued an approach for mathematical investigations with a variety of subjects using different resources, iii) the participants accept the invitation and engage in Conversations.

\footnotetext{
Doutorando em Educação Matemática pela Universidade Estadual Paulista “Júlio de Mesquita Filho”, professor da Universidade Estadual de Goiás, possui experiência na formação de professores de Matemática e pesquisa o uso de novas tecnologias, como o computador, para o ensino e para a aprendizagem da Matemática; atualmente, pesquisa a educação matemática para a terceira idade (lucianoebenezer@yahoo.com.br)

2 Doutora em Educação pela Universidade Estadual de Campinas, professor nos cursos de graduação e de pós- graduação em Educação Matemática; desenvolve pesquisas sobre o uso de tecnologia da informação e educação na organização de espaços de ensino e aprendizagem da matemática na perspectiva da educação matemática crítica e têm como foco a formação de professores, parceria universidade e escola, educação a distância e educação matemática para estudantes com necessidades especiais (mirgps@rc.unesp.br)
} 
KEYWORDS: Mathematics education. Education for the elderly. University extension.

\section{INTRODUÇÃO}

Este artigo apresenta algumas reflexões sobre atividades matemáticas desenvolvidas em uma ação extensionista com pessoas na terceira idade e adultos maduros. A temática surge do interesse dos autores em entender como Conversas sobre matemática podem fazer parte do rol de atividades para pessoas idosas.

O grupo de pessoas com mais de 60 anos vem apresentando um crescimento significativo nas últimas décadas. Assim como ocorre com todas as criaturas vivas, os seres humanos envelhecem e, na história da humanidade, sempre houve pessoas idosas. O que difere é que, enquanto no passado os idosos representavam pequenas parcelas da sociedade, atualmente a pirâmide populacional está se invertendo.

Segundo Baltes (1995, p. 12), “populações compostas por um grande número de pessoas idosas são eventos jovens, isto é, têm um advento recente na evolução humana". De acordo com o Instituto Brasileiro de Geografia e Estatística (IBGE), a população brasileira com idade igual ou superior a 60 anos ultrapassará 28 milhões, no ano de 2020, e 40 milhões, no ano de 2030, o que excederá em 11 milhões a quantidade de pessoas na faixa de 15 a 24 anos de idade.

O atual envelhecimento populacional e a longevidade vêm apresentando à sociedade desafios sobre como garantir qualidade de vida e possibilidades de realização do potencial que existe em cada uma dessas pessoas. Como consequência direta, a sociedade passa a dar mais atenção a essas pessoas.

O Estatuto do Idoso, lei $\mathrm{n}^{\mathrm{o}} 10.741$ de $1^{\circ}$ de outubro de 2003, em seu artigo terceiro estabelece ser

[...] obrigação da família, da comunidade, da sociedade e do Poder Público assegurar ao idoso, com absoluta prioridade, a efetivação do direito à vida, à saúde, à alimentação, à educação, à cultura, ao esporte, ao lazer, ao trabalho, à cidadania, à liberdade, à dignidade, ao respeito e à convivência familiar e comunitária. (BRASIL, 2003).

Como instituído em lei, a educação também é um direito do idoso. Mas por que investir em ações educativas para essas pessoas? Para Cachioni e Palma (2006), investimentos na educação de pessoas idosas se justificam porque: i) há, atualmente, um grande número de adultos maduros e pessoas idosas com maior disponibilidade de tempo para atividades desvinculadas do mundo do trabalho, implicando em outras maneiras de utilização do tempo; ii) a velhice que se delineia nos dias atuais é mais autônoma comparada à do passado; iii) a educação tradicional está aquém das mudanças sofridas pela sociedade.

Assim, ultimamente, pode-se entender que atingir a terceira idade não tem significado o fim da realização de novos projetos. As pessoas estão vivendo mais e, consequentemente, podem fazer planos futuros de médio e até de longo prazo. Tais planos envolvem, inclusive, atividades 
educativas, como mostram Lima e Penteado (2011) ao realizarem um estudo de literatura sobre possibilidades de educação para pessoas idosas. Esses pesquisadores entendem que a educação é um processo ininterrupto que ocorre em qualquer circunstância, desencadeada pelas transformações que o indivíduo passa, seja no aspecto social, político ou cultural no decorrer de sua vida, e que permite ao ser humano diferentes formas de acesso ao saber e à cultura nas mais variadas idades, sem limite de tempo ou de lugar. Consideram que aprender coisas novas na terceira idade pode proporcionar acesso a instrumentos que garantem uma maior compreensão do mundo e que resultam em uma participação mais efetiva na sociedade.

A escolha e a oportunidade de frequentar um ambiente educativo podem resultar em transformações na vida de pessoas idosas nos âmbitos físico, social e psicológico. No aspecto físico, tornam-se pessoas mais dinâmicas e saudáveis; socialmente, ampliam o número de relacionamentos por meio da participação em eventos que lhes proporcionam mais segurança e desenvoltura; já no aspecto psicológico, melhoram a autoestima e a autoimagem. Tais fatores implicam na conquista de uma maior autonomia, podendo, inclusive, contribuir para que se tornem menos inflexíveis e mais abertas às mudanças a fim de continuarem exercendo um papel ativo na sociedade (CACHIONI; NERI, 2004; CACHIONI; PALMA, 2006; ALVES, 2007; BRANCO, 2007; PINHEIRO, 2009; LARA, 2010; DIAS, 2010; PEREIRA, 2010).

Na velhice, a busca por uma realização pessoal, por meio da educação, pode contribuir com o desenvolvimento e o aperfeiçoamento do potencial cognitivo. Como bem colocado por Freire (1998, p. 85), estamos em constante processo de aprendizagem, pois "não somos, estamos sendo" Nesse sentido, estar na idade madura não representa um empecilho para aprender coisas novas.

Em um ambiente educacional, como salienta Freire (1970; 1998), são necessárias condições para que o aprendiz construa o conhecimento do objeto de estudo. Para isto, ele aconselha o estabelecimento de um diálogo entre os envolvidos nesse processo, visando à promoção de um espírito crítico e investigativo, fundamental para a construção da autonomia do sujeito "aprendente". Este pesquisador considera que, em um ambiente assim, quem ensina aprende ao ensinar e, quem aprende, ensina ao aprender.

Concordando com o autor, em relação a valorizar uma abordagem dialógica em um ambiente educativo com pessoas na terceira idade, faz-se necessário reconhecer uma maior heterogeneidade nesse segmento e se pautar no respeito às pessoas, sem distinção de classe social, profissão ou nível de escolaridade dos indivíduos. Afinal, um idoso, ou um adulto maduro, quando decide retomar os estudos, é movido pelo "desejo de conhecer, de estar atualizado, de fazer parte do mundo e nele se desenvolver, de conquistar a própria cidadania” (CACHIONI; PALMA, 2006, p. 1458).

Também é importante levar em consideração que a maturidade adquirida com o envelhecimento possibilita uma avaliação crítica da vida, visto que as experiências acumuladas podem tornar as pessoas mais detalhistas e pacientes (JORDÃO NETTO, 2001). Um tempo livre maior, possibilitado pelo afastamento de responsabilidades outras, pode potencializar questionamentos acerca de assuntos os mais variados.

O Estatuto do Idoso (BRASIL, 2003, p. 79), em seu capítulo V, artigo 21, estabelece, dentre outros 
direitos e deveres, que "o Poder Público criará oportunidades de acesso do idoso à educação, adequando currículos, metodologias e material didático aos programas educacionais a ele destinados".

Percebe-se, no Estatuto, uma preocupação em relação à abordagem pedagógica para um trabalho educacional de pessoas da terceira idade, que pode ser tanto formal quanto não formal. Por educação não formal compreendemos aquela que se caracteriza por poder escolher "seus conteúdos, métodos e objetivos, livre de constrangimentos das instruções oficiais, [e que] se dirige a um público não cativo, por não participar do jogo de atestados sociais que os diplomas estabelecem" (SIMSON et al., 2001, p. 62).

O interesse de pessoas idosas pela educação foi estudado por Velasco (2006), a partir de entrevista feita com 40 participantes de quatro Faculdades Abertas à Terceira Idade. A pesquisa mostrou que frequentar tais instituições contribui para uma autovalorização, bem como uma melhora no ambiente familiar do idoso. Resultado similar foi encontrado por Coura (2007) ao entrevistar pessoas idosas alfabetizadas que retomaram os estudos não para buscar a inserção, a permanência ou a reinserção no mercado de trabalho.

Para Goldman (2003, p. 119), deveria ser da Universidade a responsabilidade de

[...] resgatar, a essa população mais idosa, a cidadania pela educação, pela aquisição de novos e pela atualização de conhecimentos, de motivar os velhos a se articularem com as demais gerações e de proporcionar ferramentas para uma cidadania possível.

A promoção de ações educativas, para uma inserção social do idoso de forma digna, pode ser uma das alternativas adotadas para que essas pessoas se atualizem, acompanhando o presente ritmo acelerado de mudanças da sociedade (VILLANI, 2007). É relevante salientar que um trabalho educacional dirigido às pessoas na terceira idade precisa ajustar objetivos, conteúdos e métodos de acordo com os interesses e as necessidades dessa faixa etária (CACHIONI, 2003, p. 21).

Levando em conta as considerações feitas até o momento, busca-se, com o presente texto, refletir sobre possibilidades de educação matemática para pessoas com mais vivência. Para isso, relatamos uma das atividades que ocorreu nas Conversas sobre matemática, uma ação extensionista desenvolvida com adultos maduros e pessoas na terceira idade.

\section{Conversas}

As Conversas sobre matemática, ou simplesmente Conversas, como o próprio nome sugere, são diálogos que envolvem assuntos matemáticos analisados, discutidos e compartilhados em grupo. Nelas, valorizam-se as vivências dos participantes, assim como suas impressões sobre o objeto de estudo. Nesse processo ocorrem análises, compartilhamento de ideias e argumentações matemáticas, visando contribuir para um desenvolvimento das capacidades cognitivas de observar, comparar, classificar e ordenar. 
Para estimular uma Conversa, ou seja, para que o convite à participação tenha uma maior possibilidade de ser aceito, utilizam-se problemas, desafios, análise de notícias jornalísticas e jogos, geralmente desenvolvidos com o uso de recursos como materiais manipulativos, calculadoras, computador e projetor multimídia.

A proposta de Conversas sobre matemática está intimamente ligada à ideia de extensão universitária que defendemos, ou seja, uma ação comunicativa. A extensão vista como uma ação de levar, de transferir, de entregar, de depositar algo em alguém tem a pretensão de substituir uma forma de conhecimento por outra. Contudo, o conhecimento não se dá por esse caminho. Para promovê-lo, faz-se necessária uma ação que transforme a realidade por meio de uma reflexão crítica sobre o ato de conhecer, pelo qual o sujeito "se reconhece conhecendo e, ao reconhecer-se assim, percebe o 'como' de seu conhecer e os condicionamentos a que está submetido seu ato" (FREIRE, 2011, p. 29). Como uma ação comunicativa, a extensão permite um compartilhamento e uma socialização de conhecimentos, implicando em uma participação ativa dos envolvidos na discussão de um determinado objeto de estudo.

No caso das Conversas, agia-se conforme uma proposta de investigação matemática. Nesse ambiente, uma participação ativa evidenciava-se no aceite para desenvolver as atividades matemáticas, no levantamento e teste de conjecturas, e no compartilhamento das conclusões com argumentações embasadas matematicamente (SKOVSMOSE, 2000; PONTE, BROCARDO; OLIVEIRA, 2005).

Para que o convite à participação tivesse mais probabilidade de ser aceito, foram utilizados recursos variados, como fichas de investigação, calculadoras, jogos, vídeos, computador, materiais manipuláveis, dentre outros. Entendemos que a utilização de materiais adequados pode favorecer a experimentação e a descoberta de significados, tornando o estudo da matemática mais atraente e acessível. O uso de recursos foi precedido por um planejamento para a organização de possíveis caminhos que estivessem de acordo com o perfil dos participantes, assim como dos assuntos matemáticos conversados (BRASIL, 1998; BITTAR; FREITAS, 2005; LORENZATO, 2006).

\section{Os encontros}

Os encontros foram desenvolvidos por meio de uma ação extensionista que ocorreu, semanalmente, no segundo semestre do ano de 2011, com duração de, aproximadamente, uma hora, em uma universidade pública do interior de São Paulo e contou com a participação de um grupo de idosos e adultos maduros, frequentadores de um projeto desenvolvido pelo grupo de um programa de atividade física para pacientes com doença de Parkinson, visando investigar o desenvolvimento dos componentes da capacidade funcional (resistência, força, flexibilidade etc.), das funções cognitivas e da mobilidade.

AtivaMente é uma proposta deste Programa, com atividades que envolvem raciocínio lógicomatemático com o intuito de contribuir com a manutenção e o desenvolvimento das funções cognitivas dos participantes. É aqui que entra a matemática com as Conversas. 
O grupo aqui referenciado era composto por 22 pessoas, de 56 a 84 anos de idade, sendo que a maioria já se conhecia de anos anteriores por meio do projeto. Vale observar que esta foi a primeira vez que participavam de atividades com matemática neste Programa. O Quadro 1 apresenta o nível de escolaridade dos participantes. Nele é possível perceber a heterogeneidade deste aspecto no grupo.

Quadro 1 - Escolaridade.

\begin{tabular}{cc}
\hline $\begin{array}{c}\text { Quantidade } \\
\text { de pessoas }\end{array}$ & $\begin{array}{c}\text { Anos de } \\
\text { escolaridade }\end{array}$ \\
\hline 3 & 0 \\
1 & 1 \\
2 & 3 \\
7 & 4 \\
1 & 5 \\
2 & 8 \\
2 & 11 \\
1 & 12 \\
1 & 13 \\
1 & 14 \\
1 & 15 \\
\hline
\end{tabular}

Fonte: Elaborado pelos autores.

Diante disso, as atividades matemáticas propostas foram organizadas, considerando-se a heterogeneidade em relação aos anos de escolaridade. Procuramos seguir a recomendação de Santos e Sá (2000, p. 94), que afirmam ser necessário criar condições para uma participação ativa de todos do grupo, "cuidando para que a convivência com as outras pessoas - que muitas vezes possuem nível cultural mais ou menos elevado - possa ser a mais saudável possível”.

No processo de planejamento e realização das atividades, contamos com a colaboração de pósgraduandos em Educação Matemática e de graduandos em Matemática. No que diz respeito à metodologia, houve a preocupação de se evitar repetir o padrão de aulas que ocorrem em escolas, no qual um professor explica, mostra exemplos e solicita que se façam exercícios de casos parecidos. Essa abordagem, criticada para escolas em geral, certamente, não é a mais adequada para o caso, uma vez que se pretende, com a proposta, estimular um envolvimento no desenvolvimento das tarefas sugeridas.

Uma abordagem investigativa, como propõe Skovsmose (2000), possibilita uma participação ativa dos envolvidos em seu processo de aprendizagem. O pesquisador dinamarquês, assim como Ponte, Brocardo e Oliveira (2005), observa que, em um ensino baseado em investigação, não há um transmissor ativo de informações e receptores passivos, como em situações tradicionais de ensino. Para ele (2000), há um ambiente em que os participantes, ao aceitarem o convite para o desenvolvimento das atividades, assumem uma responsabilidade em procurar soluções, de forma mais autônoma, para as situações investigadas. Com isto, ambos podem produzir conhecimentos 
matemáticos. É essa postura que procuramos seguir no desenvolvimento do trabalho com os idosos. No Quadro 2, compartilhamos o nome, uma descrição sucinta e os objetivos de algumas das Conversas que tivemos.

Quadro 2 - Atividades Matemáticas.

\begin{tabular}{|c|c|c|}
\hline Atividade & Descrição & Objetivos \\
\hline Tangram & $\begin{array}{c}\text { Jogo quebra-cabeça chinês } \\
\text { composto por } 7 \text { peças geométricas } \\
\text { planas: } 5 \text { triângulos, } 1 \text { quadrado e } 1 \\
\text { paralelogramo. }\end{array}$ & $\begin{array}{l}\text { Identificar, comparar, descrever } \\
\text { e formar figuras com as peças do } \\
\text { Tangram. }\end{array}$ \\
\hline \multirow{3}{*}{ Blocos Lógicos } & $\begin{array}{l}\text { Jogo composto por } 48 \text { peças } \\
\text { geométricas de cores e formas } \\
\text { distintas. }\end{array}$ & $\begin{array}{c}\text { Reconhecer as formas geométricas } \\
\text { dos blocos lógicos. }\end{array}$ \\
\hline & $\begin{array}{l}\text { Agrupar figuras de acordo com } \\
\text { suas formas. }\end{array}$ & $\begin{array}{l}\text { Comparar cores, tamanhos e } \\
\text { formas. }\end{array}$ \\
\hline & $\begin{array}{l}\text { Jogar um dominó de formas } \\
\text { lógicas. }\end{array}$ & \\
\hline Calculadoras & $\begin{array}{l}\text { Realizar de cálculos matemáticos, } \\
\text { utilizando uma calculadora. }\end{array}$ & $\begin{array}{l}\text { Descobrir a lei de formação de } \\
\text { uma sequência de multiplicações }\end{array}$ \\
\hline Lógica & $\begin{array}{l}\text { Sequências de figuras em que é } \\
\text { necessário descobrir o que falta } \\
\text { para completar a sequência. }\end{array}$ & $\begin{array}{c}\text { Encontrar padrões em sequências } \\
\text { de figuras e em sequências } \\
\text { numéricas. }\end{array}$ \\
\hline $\begin{array}{c}\text { Bingo } \\
\text { Matemático }\end{array}$ & $\begin{array}{l}\text { Jogo de bingo em que o número a } \\
\text { ser anotado na cartela é o resultado } \\
\text { de uma sentença matemática. }\end{array}$ & $\begin{array}{l}\text { Realizar cálculos mentais e } \\
\text { com lápis e papel, envolvendo a } \\
\text { operação de adição. }\end{array}$ \\
\hline Confraternização & $\begin{array}{l}\text { Elaboração de lista de compra para } \\
\text { uma confraternização. }\end{array}$ & $\begin{array}{l}\text { Organizar o que seria feito } \\
\text { numa confraternização, comidas } \\
\text { e bebidas. Calcular o gasto } \\
\text { total e o gasto de cada um dos } \\
\text { participantes. }\end{array}$ \\
\hline $\begin{array}{l}\text { Empréstimo para } \\
\text { aposentados }\end{array}$ & $\begin{array}{l}\text { Vídeo com reportagem sobre } \\
\text { empréstimos para aposentados e } \\
\text { atividades com tabelas, envolvendo } \\
\text { cálculos com porcentagem. }\end{array}$ & $\begin{array}{l}\text { Dialogar sobre a necessidade de } \\
\text { se fazer um empréstimo. } \\
\text { Entender como se deduz o valor } \\
\text { do empréstimo da aposentadoria } \\
\text { ou benefício. }\end{array}$ \\
\hline
\end{tabular}

Fonte: Elaborado pelos autores. 
Na organização e no desenvolvimento das atividades, levamos em consideração as recomendações de Zimerman (2000, p. 47), referentes aos cuidados necessários para um trabalho com idosos. Para a autora, é importante:

1. Respeitar as individualidades, evitando as generalizações.

2. Não infantilizá-los.

3. Não tratá-los como doentes.

4. Não tratá-los como incapazes.

5. Oferecer-lhes cuidados específicos para sua faixa etária.

6. Preservar sua independência e autonomia.

7. Ajudá-los a desenvolver aptidões.

8. Ter paciência, pois seu tempo é outro, são mais lentos.

9. Trabalhar suas perdas e seus ganhos.

10. Promover muita estimulação biopsicossocial.

Zimerman (2000) também sugere que se preste atenção às condições físicas dos idosos e, quando necessário, se adeque as atividades. Para aqueles com alguma dificuldade visual, por exemplo, é possível utilizar as tecnologias que permitem ampliar a fonte de textos. Se o problema for auditivo, sugere que se fale mais alto, lembrando-se de pronunciar lentamente as palavras. Ter essa sensibilidade no trabalho faz diferença quando há a preocupação com a participação de todos.

Na próxima seção, trazemos considerações mais detalhadas sobre uma Conversa em que utilizamos como recurso os blocos lógicos para a exploração de formas geométricas.

\section{Barricada, bandeiras, escola, jóquei clube... e a determinação da área de um círculo}

O trabalho com blocos lógicos (Figura 1) permitiu a manutenção de um diálogo envolvendo as características das peças, formas de agrupá-las e possíveis relações entre elas.

Distribuímos uma caixa com os blocos para cada uma das sete duplas que se formaram neste encontro. A primeira tarefa foi determinar a quantidade de peças em cada caixa. Cada integrante contou uma porção e, ao final, o grupo somou os resultados parciais para encontrar o total.

Para a familiarização com as peças, solicitamos que representassem uma figura qualquer, composta 
pelas peças individuais. Os participantes foram bem criativos e diversificados. Um senhor, por exemplo, disse que fezuma barricada, apontando as peças que representavam o local em que as pessoas se abrigariam de possíveis flechas de índios (Figura 2). Estimulado por um dos membros da equipe dinamizadora, ele comentou que gostava de filmes de faroeste e que havia assistido a vários deles.

Figura 1 - Blocos Lógicos.

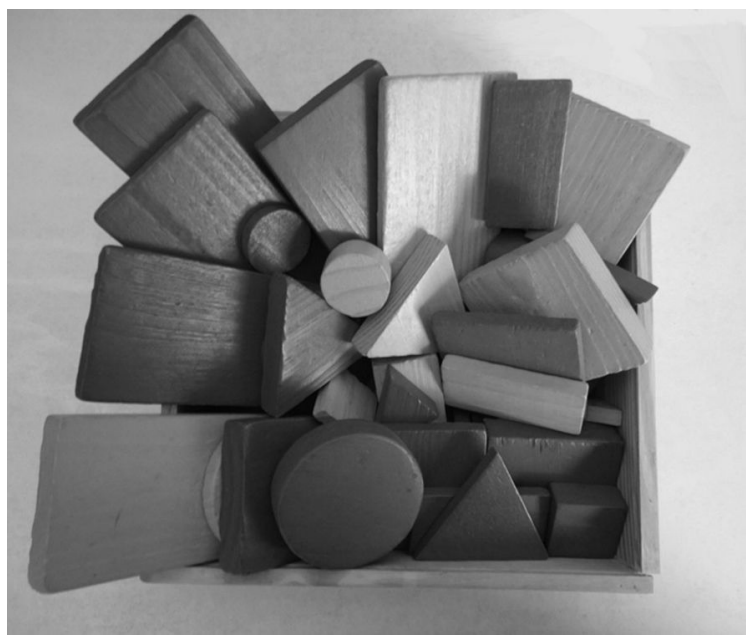

Fonte: Acervo dos autores.
Figura 2 - Representação de uma barricada.

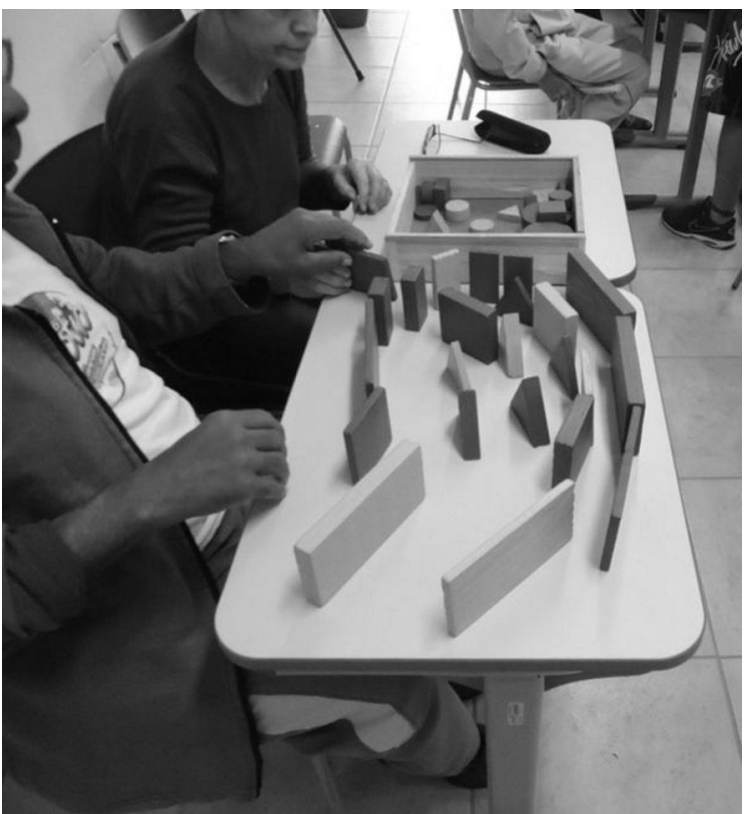

Fonte: Acervo dos autores.

Uma dupla utilizou vários prismas de base retangular e de base quadrada, todos amarelos, inserindo um prisma de base circular vermelho no centro para representar a bandeira do Japão (Figura 3). Questionados sobre o uso da cor amarela, responderam que fizeram assim porque não havia peças de cor branca. Eles também representaram uma sala de aula. Nota-se que o ambiente escolar foi representado por prismas de base retangular e de base quadrada, todos de cor azul, e as pessoas, por prismas de base triangular "como se estivessem com a cabeça para cima", conforme explicação da dupla (Figura 3). Outros representaram a bandeira brasileira com um prisma de base retangular azul, sobreposto por um prisma amarelo de base quadrada e, sobre este último, havia um prisma de base circular azul, como na Figura 4. 
Figura 3 - Bandeira do Japão e sala de aula.

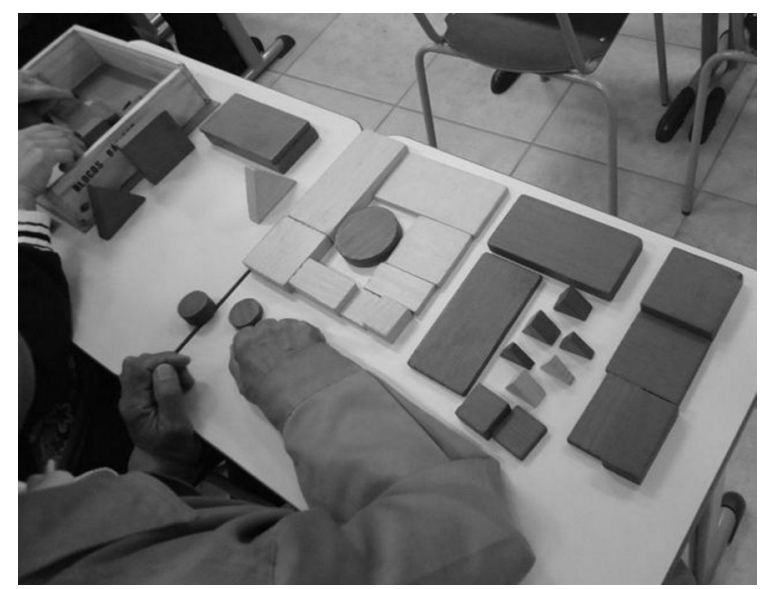

Fonte: Acervo dos autores.

Figura 5 - Representação de uma igreja.

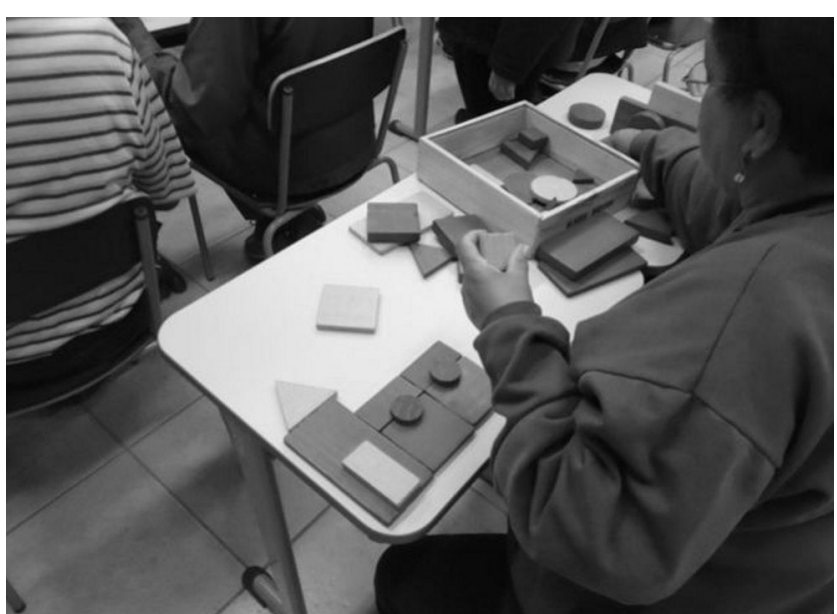

Fonte: Acervo dos autores.
Figura 4 - Bandeira do Brasil.

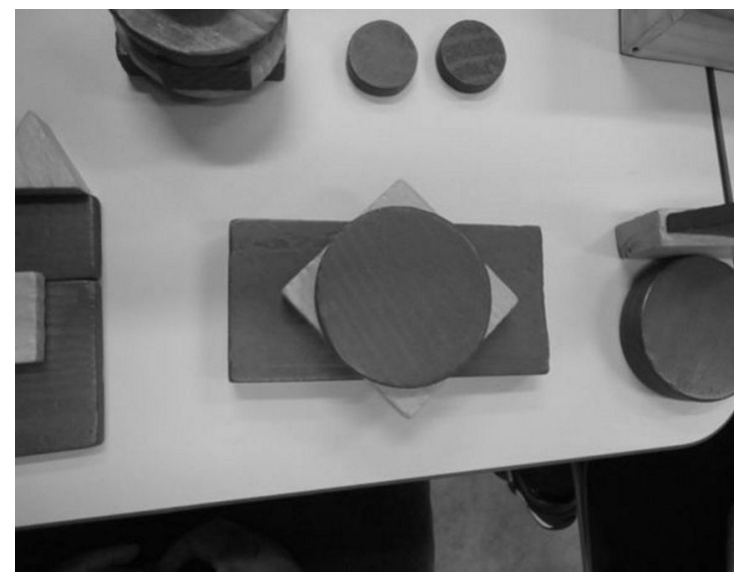

Fonte: Acervo dos autores.
Figura 6 - Representação de um jóquei-clube.

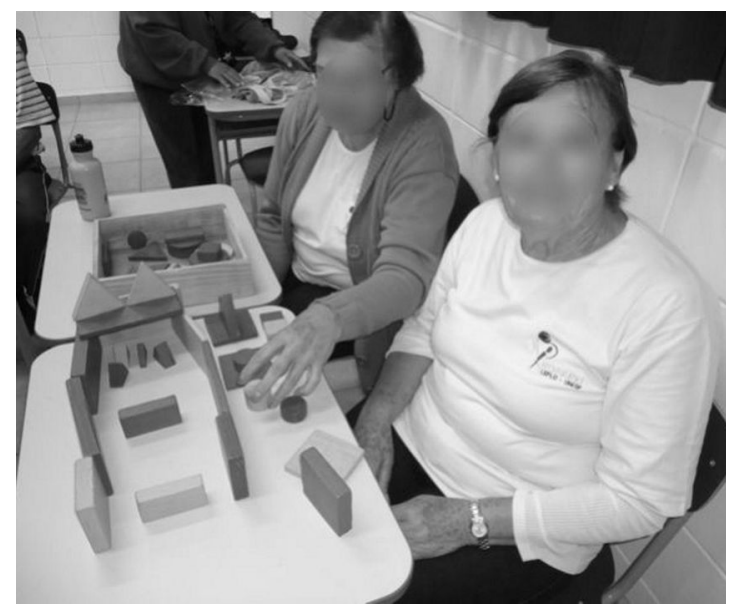

Fonte: Acervo dos autores.

Duas outras senhoras, de duplas diferentes, representaram uma escola e relataram que uma dessas representações incluía o professor, o diretor e os alunos. A outra representação continha a disposição dos alunos - voltados para um quadro - e o professor entre os dois ambientes.

Uma participante representou uma igreja (Figura 5). Outra idealizou um jóquei-clube, ressaltando qual seria a entrada dos cavalos, com seus respectivos jóqueis, além de mostrar a necessidade das baias e portões pelos quais sairiam no início da prova, conforme Figura 6 .

Após essa atividade de familiarização, passamos à fase de exploração das características de cada peça. Perguntamos sobre cor, espessura e tamanho. Todos responderam prontamente que havia três cores diferentes (amarela, vermelha e azul), duas espessuras (grossa e fina) e dois tipos de tamanho (grande e pequeno). Exploramos as formas geométricas por meio de perguntas, tais como: 
Que formas geométricas vocês encontraram? Resposta: Quadrado, triângulo, retângulo e círculo.

Pedimos que mostrassem uma figura com formato quadrado e que respondessem o que garantia que, de fato, aquilo era um quadrado. Eles pensaram um pouco e um senhor respondeu que, para ser um quadrado, todos os lados deveriam ser iguais. Todos do grupo concordaram com essa explicação.

Para verificar a validade dessa justificativa, pediu-se para que juntassem dois triângulos equiláteros formando uma única peça com quatro lados iguais, conforme representado na Figura 7.

Figura 7 - Representação de um losango.

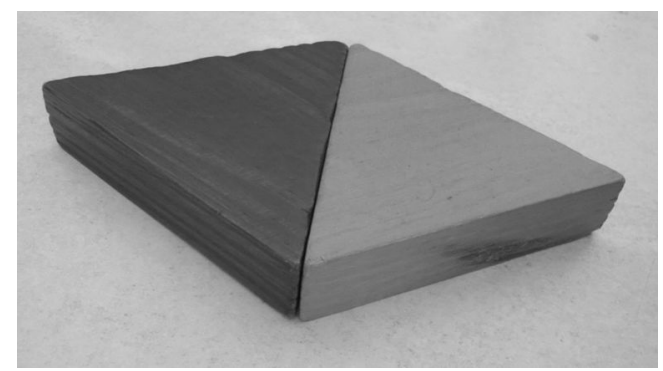

Fonte: Acervo dos autores.
Figura 8 - Formas triangulares.

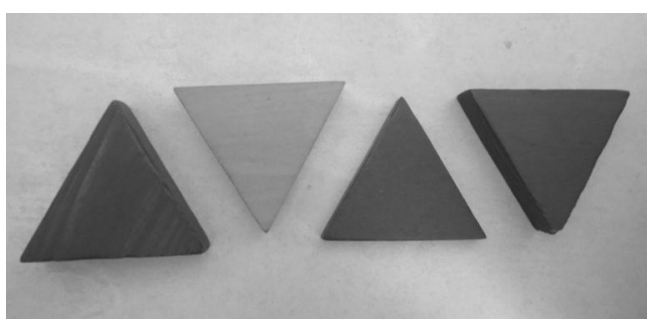

Fonte: Acervo dos autores.

Questionamos se essa figura poderia representar um quadrado. Outro senhor respondeu que não e disse que a figura formada representava um losango. Constataram, assim, que para uma figura ser um quadrado não bastava possuir quatro lados de medidas iguais.

Foi preciso que pensassem um pouco mais para responder, o que dava a garantia de que uma figura seria um quadrado. Passado um tempo não muito longo, uma senhora respondeu que para ser um quadrado, a figura, além de ter os quatro lados iguais, teria que ter quatro ângulos retos, ou seja, que medissem 90 graus.

Seguimos para a exploração da forma retangular, com a seguinte pergunta: O que garante que uma figura seja um retângulo? Rapidamente, uma senhora respondeu que um retângulo deveria ter os quatro ângulos retos e lados iguais, dois a dois. Questionada sobre se estava se referindo aos lados opostos, ela respondeu que sim, complementando que os lados opostos deveriam ser iguais.

No caso das formas triangulares, exploramos a classificação das peças de acordo com seus lados. Diante da pergunta “que tipos de triângulos são esses?" (Figura 8), uma senhora respondeu que eram triângulos isósceles. Comentamos que ela estava correta, mas que havia outra classificação possível. Diante disso, alguém lembrou que aqueles triângulos eram equiláteros, ou seja, eles possuíam os três lados iguais. Aproveitando a conversa sobre o triângulo equilátero, perguntamos quanto mediam seus ângulos internos, a que alguém respondeu 60 graus.

Juntamos duas peças que representavam dois triângulos equiláteros, formando um losango e, novamente, questionamos o motivo de esses dois triângulos unidos não representarem um quadrado. $\mathrm{O}$ grupo constatou que os ângulos internos, quando unimos dois triângulos equiláteros, formando um losango, mediam $60^{\circ}, 120^{\circ}, 60^{\circ}$ e $120^{\circ}$ e, devido a isso, a figura não poderia ser um quadrado como havíamos discutido anteriormente. 
O diálogo sobre as características das formas geométricas continuou. Questionamos sobre as relações entre as peças que compõem os blocos lógicos com perguntas do tipo:

a. Quantas peças, das que representam os quadrados pequenos, são necessárias para formar uma peça que representa um quadrado grande?

b. Quantas peças, das que representam os quadrados pequenos, são necessárias para formar uma peça que representa um retângulo grande?

c. Quantas peças, das que representam os triângulos pequenos, são necessárias para formar uma peça que representa um triângulo grande?

d. Quantas peças, das que representam os quadrados pequenos, são necessárias para formar uma peça que representa um retângulo pequeno? E um grande?

e. Quantas peças, das que representam os retângulos pequenos, são necessárias para formar uma peça que representa um quadrado grande? E um retângulo grande?

Para cada um desses questionamentos, os participantes eram convidados a fazer sobreposições nas peças para conferir se as respostas estavam corretas (Figura 9). Esperávamos todas as duplas fazerem suas observações, testando suas ideias. A manipulação do material pareceu motivar a todos, pois cada dupla queria mostrar como tinha feito.

Figura 9 - Sobreposição de peças.

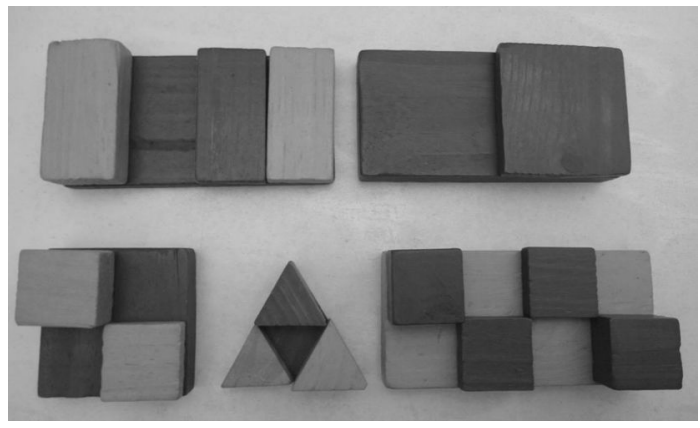

Fonte: Acervo dos autores.
Figura 10 - Sobreposição circular.

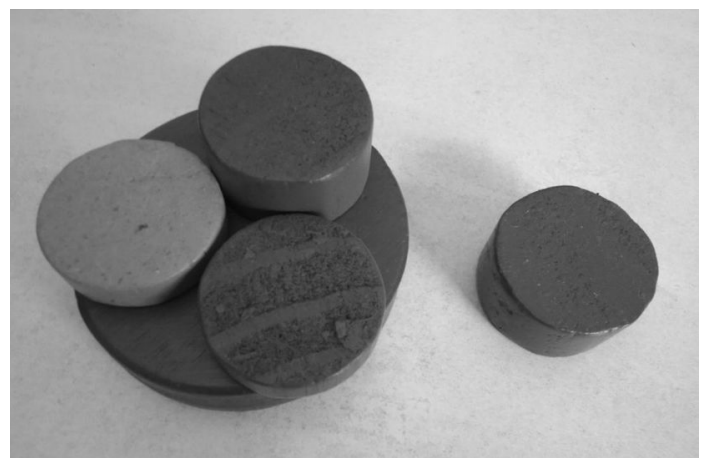

Fonte: Acervo dos autores.

Quando falávamos de sobrepor peças menores sobre uma maior, perguntávamos o que significava esse processo de sobreposição para cobrir uma superfície. Uma senhora respondeu que fazer isso era o mesmo que encontrar a área da peça maior a partir da medida de uma peça menor. Antes que fizéssemos outra pergunta, uma senhora comentou que ainda não havíamos falado do círculo. Aproveitamos a oportunidade para questionar quantos círculos menores seriam necessários para cobrir a área do círculo maior, o que motivou todos a fazerem experimentações, colocando os círculos menores (escrevemos $C_{p}$ para as peças que representam círculo pequeno) sobre um dos maiores (escrevemos $C_{g}$ para as peças que representam círculo grande). Ao fazer isso, perceberam que os círculos menores não preenchiam completamente a área do círculo maior, como visto na Figura 10. 
"E agora?" - perguntaram. O grupo queria saber qual conclusão tirar. Sabemos que a medida da área do $C_{p}$ é um quarto da medida da área do $C_{g}$, afinal, considerando r o raio do $C_{g}$ temos $A_{g}=\pi r^{2}$ ( $A_{g}$ : área do círculo grande) e como o raio do círculo pequeno é $r / 2$ sua área mede $A_{p}^{g}=1 / 4 \pi r^{2}\left(A_{p}\right.$ : área do círculo pequeno), ou seja, $A_{p}=1 / 4 A_{g}$, mas não queríamos fazer esses cálculos no quadro, visto que alguns idosos poderiam não entender os nossos argumentos matemáticos. Comentamos, então, que a área do círculo pequeno era um quarto da área do círculo grande, mas a forma circular não permitia a sobreposição sem deixar espaços. Todos se deram por satisfeitos.

Prosseguindo com as atividades, os convidamos para um jogo semelhante ao dominó, mas utilizando blocos lógicos. Neste, os jogadores teriam que combinar as regras entre si. Os grupos concordaram em iniciar com um quadrado grande e o próximo jogador deveria ter uma peça com duas das características da peça inicial: tamanho, espessura, forma ou cor. A partir da terceira jogada, combinaram que a próxima peça a ser encaixada deveria ter duas das características de uma das peças que estava nos extremos da sequência do jogo, como ilustra a Figura 11.

Figura 11 - Dominó com blocos lógicos.

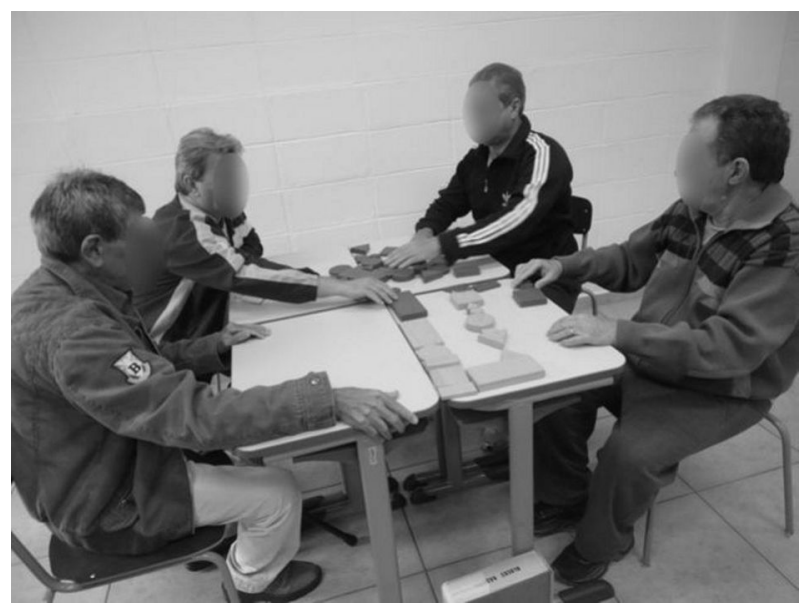

Fontes: Acervo dos autores.

Após terminarmos as atividades, pedimos para guardarem os blocos lógicos. Enquanto isso, perguntamos aos participantes se haviam gostado da Conversa. Eles afirmaram ter gostado muito de ter conversado sobre geometria com a utilização dos blocos lógicos e de tê-los utilizado para jogar.

\section{DISCUSSÃO}

A atividade descrita acima exemplifica a abordagem investigativa proposta por Skovsmose (2000) e por Ponte, Brocardo e Oliveira (2005). É possível observar que houve a formulação de questões para compreender o que era para ser feito; a elaboração de conjecturas como possibilidades de solução; o teste e o refinamento das questões e conjecturas anteriores; e a comunicação dos resultados. Neste processo, é possível observar que os participantes estabeleceram relações entre grandeza e forma, além de resgataram conhecimentos sobre geometria, tais como nomes e características de figuras geométricas. Não optamos por 
soluções escritas, mas isso é uma possibilidade que permitiria refinar as justificativas.

Durante toda a atividade, tomamos o cuidado devido para que as pessoas pudessem manifestar suas ideias sobre a situação estudada.

A ideia de se propor um jogo com as peças de blocos lógicos baseia-se em Grando (2000), que acredita que momentos de jogo, principalmente aqueles em que os jogadores determinam as regras, constituem-se como uma atividade dinâmica e prazerosa que pode motivar os jogadores à ação. O resultado da atividade com a participação de todos e as considerações do grupo em relação ao jogo nos permitem afirmar que este objetivo foi atingido.

É interessante destacar que alguns dos participantes nos informaram que a participação no grupo é a única oportunidade que têm para sair de casa e entrar em contato com pessoas diferentes. Salientese, portanto, que os frequentadores do AtivaMente tem grau de formação distinto, com idades e culturas diversas. Esse fato, associado à oportunidade de discussão de assuntos matemáticos com pós-graduandos em Educação Matemática e graduandos em Matemática, pode favorecer a formação de novos conhecimentos, uma excelente alternativa para ocupar parte do tempo livre.

Todos os participantes relataram estar satisfeitos com a oportunidade de participar das Conversas e de aprender coisas sobre matemática nesse momento da vida. É importante salientar que, ao sair de suas respectivas casas, do convívio com seus familiares, e ao participar de atividades na universidade, os idosos ingressam em um espaço repleto de conhecimentos de ponta e de ações inovadoras a eles disponíveis e acessíveis. Tal fato possibilita que compartilhem os "conhecimentos adquiridos com o grupo familiar, voltando, muitas vezes, a serem alvos de elogios e credibilidade, condição essa que vinham perdendo por estarem em processo de envelhecimento humano" (ARAÚJO et al., 2011, p. 56-57).

Com frequência, os participantes nos relatavam, tanto durante quanto após as Conversas, que estavam gostando de aprender coisas novas sobre matemática. Em diálogos informais, muitos nos diziam que gostavam de compartilhar o que aprendiam nos encontros com pessoas de seu cotidiano. Um senhor relatou que fazia as atividades em casa para "tirar da cabeça os problemas com a família". Uma senhora disse ter desenvolvido uma das atividades das Conversas com suas colegas que bordam pano de prato. Segundo ela, isso ajudava a distrair a cabeça quando estavam cansadas de bordar. A senhora mais idosa do grupo comentou, muito feliz, que, enquanto ficava no salão de beleza da filha, ensinou a uma das clientes como jogar o Tangram: "eu perguntei se ela já havia ouvido falar do Tangram e ela disse que não. Então expliquei o que era o Tangram e como fazer as figuras com ele". Isso foi possível devido ao fato de o grupo responsável pelas atividades confeccionar este quebra-cabeça em EVA, a fim de que todos os participantes pudessem levar para casa e montar as figuras representadas nas fichas de atividades quando quisessem. Todas as fichas de atividades eram fotocopiadas e entregues aos participantes, que as levavam para casa. Tentamos, na medida do possível, colocar histórias sobre o assunto discutido. No caso do Tangram, reproduzimos uma lenda sobre a origem desse tipo de quebra-cabeça.

Várias pessoas também pedirampara encaminharmos, por e-mail, oBingo Matemático, porquequeriam jogar na igreja ou em outros grupos que participavam. Muitos do grupo compartilharam que desafiavam 
netos, familiares e amigos a fazer algumas das atividades matemáticas que aprenderam nas Conversas.

Os comentários dos participantes trazem indícios de que a matemática também pode contribuir para um compartilhamento de informações entre adultos maduros e idosos com seus familiares e/ou amigos. Ou seja, as Conversas não ficaram restritas ao ambiente do grupo na universidade durante o desenvolvimento da ação extensionista.

\section{CONSIDERAÇÕES FINAIS}

A educação é um direito das pessoas idosas, e nossa experiência mostra que é possível um trabalho voltado para esse público. Por meio de atividades matemáticas, pode-se contribuir com: o resgate e uso de conhecimentos que são fruto de experiências do passado e produção de novos conhecimentos; o compartilhamento de ideias/saberes; uma maior autonomia do idoso em assuntos que, de alguma forma, envolvam raciocínios matemáticos, dentre outros. Nesse sentido, é possível estabelecer um ambiente que estimule pessoas idosas a se manterem mentalmente ativas.

As Conversas sobre matemática têm proporcionado aos participantes um contato com temáticas deles desconhecidas e isso pode contribuir para uma melhora da autoestima e da autoimagem. Participar de espaços educativos pode ser para o idoso uma forma de reinserção cultural, por ocupar parte de seu tempo com o aprendizado de coisas novas.

Para tornar o ambiente propício a um engajamento individual e coletivo no processo, temos valorizado a diversidade de saberes por meio de um diálogo aberto e respeitoso, aproveitando as vivências que os participantes verbalizam com criatividade na apresentação dos assuntos matemáticos.

No ambiente promovido pelas Conversas, os idosos sentem-se pertencentes e participantes de um grupo. Com isto, ficam à vontade para expressar livremente suas ideias. Por exemplo, em uma atividade envolvendo Quadrados Mágicos foi sugerido que os participantes utilizassem as calculadoras disponibilizadas para calcular a soma dos números nas linhas, colunas e diagonais de um Quadrado Mágico 4 por 4, representado no quadro Melancolia I, do pintor Albrecht Dürer (1471-1528), ao que uma senhora interveio: "você quer que utilizemos calculadoras, mas no nosso tempo fazíamos contas de cabeça e utilizávamos os dedos".

Ela foi incentivada a explicar seu raciocínio para os cálculos pedidos, o que fez prontamente: "para a soma dos números da primeira linha 16, 3, 2 e 13, primeiramente, eu calculo $16+13$ $=29$, depois faço $3+2=5$ e, finalmente, adiciono 5 aos 29 " e utilizou os dedos da mão como recurso de cálculo para dar a resposta. Seguindo seu exemplo, os demais participantes também desejaram compartilhar como faziam as adições no Quadrado Mágico.

Nos encontros, foram vários os momentos em que os participantes mostraram desenvoltura para expressar seus pontos de vista, como em uma Conversa envolvendo uma notícia jornalística sobre empréstimo para aposentados. Após assistir a um vídeo sobre este assunto, o grupo considerou questões que não estavam contempladas na reportagem como: valores cobrados pelos planos de 
saúde versus valor do salário mínimo.

Em todos os encontros, os participantes se sentiram à vontade para expressar suas vivências e pontos de vista. Faziam comparações, levantamento de conjecturas, testes e defesa de ideias nas Conversas que tivemos. A vontade de aprender, participar das atividades, compartilhar conhecimentos e a alegria de estar junto em um grupo composto por outros colegas idosos, graduandos e pós-graduandos mostrou-se uma constante em todos os encontros.

Constatamos a alegria dos participantes em fazer parte do grupo através de observações realizadas pelos responsáveis pelo desenvolvimento das atividades e em conversas informais com membros do grupo. Nesses momentos, como proponentes das atividades, também ficamos muito felizes e entusiasmados ao ouvir de vários idosos que compartilhavam as atividades das Conversas com familiares e amigos.

Diante disso, pensamos que Conversas sobre matemática com pessoas na terceira idade podem fazer parte do rol de atividades para este público se: i) forem entendidas como uma ação comunicativa que promova uma produção compartilhada de conhecimentos com acadêmicos e participantes trabalhando colaborativamente; ii) for valorizada uma abordagem com investigações matemáticas de assuntos variados, utilizando diferentes recursos; iii) os participantes aceitarem o convite e envolverem-se nas Conversas.

Nas Conversas buscou-se, constantemente, estimular a participação nas atividades sugeridas. Embora os membros do grupo estivessem longe dos bancos escolares há algum tempo, nos encontros, eles recordaram vários conceitos matemáticos e argumentaram de forma bastante satisfatória. Em momentos de jogo, por exemplo, foi possível discutir/estabelecer as regras a serem seguidas e as prováveis estratégias para se ganhar uma partida.

Atividades como as desenvolvidas permitem que a universidade se abra para ensinar e, ao mesmo tempo, aprender com os idosos em um processo educativo que valoriza o engajamento individual e coletivo, respeitando a diversidade de saberes, os limites e as potencialidades de cada sujeito. A extensão universitária pode ser uma forma de desenvolver atividades deste tipo, aproximando a universidade a outros setores da sociedade. No caso do trabalho apresentado, a aproximação com os idosos viabilizou que graduandos, pós-graduandos e professores-pesquisadores produzissem, colaborativamente com os participantes, conhecimento sobre assuntos que são uma demanda social.

Ações extensionistas voltadas para a matemática, contemplando um público de idosos e adultos maduros ainda são raras. Contudo entendemos que elas podem contribuir para a inserção e a participação desses indivíduos na sociedade, assim como para um aumento da autoestima e da valorização dos saberes dos mais velhos. 


\section{AGRADECIMENTOS}

Agradecemos a Bruno Bertoncello pela leitura e sugestões que muito contribuíram para a versão final deste texto e aos alunos da graduação em Matemática Gabrielle Saldanha, Matheus Scagion e José Renato Buzolin que auxiliaram com a elaboração e o desenvolvimento das atividades.

\section{REFERÊNCIAS}

ALVES, E. M. S. O idoso na sala de aula: um novo ator. 2007. Dissertação (Mestrado em Educação) - Universidade Católica de Brasília, Brasília, 2007.

ARAÚJO, M. A. M. et al. Extensão universitária um laboratório social. São Paulo: Cultura Acadêmica, 2011.

BALTES, P. B. Prefácio. In: NERI, A. L. (Org.). Psicologia do envelhecimento: temas selecionados na perspectiva de curso de vida. Campinas, SP: Papirus, 1995.

BITTAR, M.; FREITAS, J. L. M. Fundamentos e metodologia de matemática para os ciclos iniciais do ensino fundamental. 2. ed. Campo Grande: Editora da UFMS, 2005.

BRANCO, P. G. Envelhecimento e educação de idosas: processos e desenvolvimentos singulares. 2007. 143 f. Dissertação (Mestrado em Gerontologia) - Pontifícia Universidade Católica de São Paulo, São Paulo. 2007.

BRASIL. Secretaria de Educação Fundamental. Parâmetros Curriculares Nacionais: Matemática. Brasília: MEC/SEF, 1998.

BRASIL. Estatuto do idoso. Lei $n^{\circ} 10.741$, de $1^{\circ}$ de outubro de 2003. Dispõe sobre o Estatuto do Idoso e dá outras providências. Brasília, DF, 2003.

CACHIONI, M. Quem educa os idosos? um estudo sobre professores de universidades da terceira idade. Campinas, SP: Alínea, 2003.

CACHIONI, M.; NERI, A. L. Educação e velhice bem-sucedida no contexto da terceira idade In: NERI, A. L.; YASSUDA, N. S. (Orgs). Velhice bem sucedida: aspectos afetivos e cognitivos. Campinas: Papirus, 2004.

CACHIONI, M.; PALMA, L. S. Educação permanente: perspectiva para o trabalho educacional com o adulto maduro e o idoso. In: FREITAS, E. V. et al. (Org.).Tratado de geriatria e gerontologia. 2. ed. Rio de Janeiro: Guanabara Koogan, 2006.

COURA, I. G. M. A terceira idade na educação de jovens e adultos: expectativas e motivações. 2007. 134 f. Dissertação (Mestrado em Educação) - Universidade Federal de Minas Gerais, Belo Horizonte. 2007. 
DIAS, F. A. Qualidade de vida de idosos e participação em atividades educativas grupais. 2010. 139 f. Dissertação (Mestrado em Atenção à Saúde) - Universidade Federal do Triângulo Mineiro, Uberaba. 2010.

FREIRE, P. Pedagogia do oprimido. Rio de Janeiro: Paz e Terra, 1970.

FREIRE, P. Pedagogia da autonomia: saberes necessários à prática educativa. São Paulo: Paz e Terra, 1998.

FREIRE, P. Extensão ou Comunicação? Tradução de Rosisca Darci de Oliveira. 15. ed. São Paulo: Paz e Terra, 2011.

GRANDO, C. R. O conhecimento matemático e o uso de jogos na sala de aula. 2000. 239 f. Tese (Doutorado em Educação) - Faculdade de Educação, Universidade Estadual de Campinas, Campinas. 2000.

GOLDMAN, S. N. Universidade para terceira idade: uma lição de cidadania. Olinda: Elógica, 2003.

IBGE. Projeção da população do Brasil por sexo e por idade (1980-2050). Disponível em: $<$ http://www.ibge.gov.br/home/estatistica/populacao/projecao_da_populacao/2008/>. Acesso em: 10 abr. 2013.

JORDÃO NETTO, A. Universidade aberta para a maturidade: avaliação crítica de uma avançada proposta educacional e social. In: KACHAR, V. (Org.). Longevidade: um novo desafio para a educação. São Paulo: Cortez, 2001.

LARA, C. R. S. A educação do idoso como fator de melhoria de sua saúde: um estudo sobre uma experiência da ESF Machado Fagundes em Cascatinha - Petrópolis. 2010. 115 f. Dissertação (Mestrado em Educação) - Universidade Católica de Petrópolis, Petrópolis, 2010.

LIMA, L. F.; PENTEADO, M. G. Educação de idosos: possibilidades. In: MELLO, M. (Org.), Universidade, pesquisa e produção do conhecimento. Goiânia: Editora da PUC Goiás, 2011.

LORENZATO, S. O laboratório de ensino de matemática na formação de professores. Campinas, SP: Autores Associados, 2006.

PEREIRA, J. M. M. A escola do riso e do esquecimento: idosos na EJA. 2010. Dissertação (Mestrado em Educação) - Universidade Federal Fluminense, Niterói, 2010.

PINHEIRO, G. A. D. Educação e envelhecimento: atividade intelectual na terceira idade. 2009. 113 f. Dissertação (Mestrado em Educação) - Universidade Estadual de Maringá, Maringá. 2009.

PONTE, J. P.; BROCADO, J. ; OLIVEIRA, H. Investigações matemáticas na sala de aula. Belo Horizonte: Autêntica, 2005. 
SANTOS, A. T.; SÁ, M. A. A. De volta às aulas: ensino e aprendizagem na terceira idade. In: NERI, A. L; FREIRE, S. A. (Org.). E por falar em boa velhice. Campinas, SP: Papirus, 2000.

SIMSON, O. R. M. et al. A valorização da diferenciação sociocultural como fator deintegração de estudantes em situação de risco: discussão de uma experiência concreta: o Projeto Sol em Paulínia (SP). In: SIMSON, O. R. M.; PARK, M. B.; FERNANDES, R. S. (Orgs.). Educação não formal: cenários da criação. Campinas/SP: Editora da UNICAMP, 2001.

SKOVSMOSE, O. Cenários para investigação. Bolema, Rio Claro, n. 14, p. 66-91, 2000.

VELASCO, C. Aprendendo a envelhecer: a luz da psicomotricidade. São Paulo: Phorte, 2006.

VILLANI, F. L. A longevidade no aprendizado de línguas: acrescentando vida aos anos e não anos à vida. 2007. 258 f. Tese (Doutorado). Pontifícia Universidade Católica de São Paulo, São Paulo. 2007.

ZIMERMAN, G. I. Velhice: aspectos biopsicossociais. Porto Alegre: Artes Médicas Sul, 2000.

Submetido em 11 de junho de 2013.

Aprovado em 29 de julho de 2013. 